\title{
Oralidad y escritura indígenas. Otros rumbos para su investigación
}

\author{
Indigenous orality and writing. Different pathways for research
}

\author{
RAúl Homero López EspinosA* \\ doi.org/10.29043/liminar.v20i1.884
}

Resumen: La relación entre oralidad y escritura es clave para comprender la literatura latinoamericana y la colonización europea de América. Se han propuesto, entre otros, conceptos como oralitura, etnotexto y etnoliteratura para la expresión artística de la oralidad indígena. Este artículo problematiza en los marcos del debate poscolonial y, en particular, de la subalternidad, términos como oralitura. Se muestra, además, cómo las maneras de nombrar aquella expresión oral indígena en franca tensión con la escritura, así como las metodologías para su estudio, están en construcción y se apuntan algunas condiciones y criterios mínimos para su abordaje interdisciplinario.

Palabras clave: oralidad, escritura, oralitura, subalternidad, interdisciplina.

Abstract: The relationship between orality and writing is key to understanding Latin American literature and the European colonization of the Americas. Concepts such as oral literature, ethnotext, and ethnoliterature have been proposed for the artistic expression of indigenous orality, among others. This article discusses oral literature referencing the postcolonial debate and, particularly, subalternity. It also offers insights into how naming indigenous oral expression is counterposed to writing. Further, we discuss the methodologies used for this study, which are under construction, and a number of conditions and minimum criteria for an interdisciplinary approach to this discipline.

Key words: orality, writing, oraliture, subalternity, inter-discipline.

* Universidad Veracruzana, Xalapa, México raullopez01@uv.mx iD 0000-0002-0568-5278 


\section{Introducción}

$\mathrm{A}$

ntonio Cornejo Polar sostuvo que la comprensión de la literatura latinoamericana necesitaba del examen de sus "mecanismos de conformación: la oralidad y la escritura" (1994, p. 19), y que esta, en los Andes, fue "un hecho de conquista y dominio" (1994, p. 39). ${ }^{1}$ La relación entre oralidad y escritura tiene implicaciones en el ámbito literario, pero también en la cultura, la ideología y, en particular, en el problema de la subalternidad, como se observa en la colonización europea de América. Esta colonización sucedió en términos territoriales, económicos, políticos y, también, epistémicos: la racionalidad eurocéntrica se impuso como el único camino transitable e invisibilizó y silenció racionalidades otras como las indígenas.

Gayatri Chakravorty Spivak (2017) afirma que en la India de los británicos el inglés se estableció no solo como instrumento de comunicación, sino como el medio para apreciar la literatura, lo cual entrañó la enajenación del subalterno pues se moldeó su pensamiento en función de patrones y valores culturales dominantes. Algo análogo sucedió en la América española con el castellano, asumido como hegemonía y vía exclusiva para producir conocimiento y arte, como lengua "legítima" cuyo poder simbólico, explica Silvia Rivera Cusicanqui (2018), silenció las lenguas indígenas. Así, el colonialismo es, para la pensadora boliviana, la incubación de formas pedagógicas en el cuerpo y en el sentido común.

El debate poscolonial cuestiona el eurocentrismo: reconoce su hegemonía, pero no su universalidad, y reivindica modos diversos de conocer, pensar, conducirse éticamente y expresarse estéticamente. En este contexto se revitalizan las lenguas indígenas y el discurso oral, los cuales son afirmados como conocimiento, historia y expresiones artísticas. Algunos esfuerzos por nombrar estas expresiones indígenas los encontramos en conceptos como oralitura, etnotexto y etnoliteratura.

Mi intención es, en primer lugar, plantear preguntas sobre el sentido que adquieren estos conceptos en el marco de discusión poscolonial. La relación entre escritura y oralidad requiere de una aproximación interdisciplinaria porque constituye un problema complejo. Esto conlleva nuevas interrogantes, ¿cómo validar epistémica y metodológicamente la interacción entre disciplinas? Así, en segundo lugar, me propongo problematizar las palabras que usamos para nombrar aquellas expresiones indígenas y las herramientas que tenemos para analizarlas, con la finalidad de anotar algunas condiciones previas para su estudio.

\section{El debate poscolonial}

Walter Ong afirma que en la escritura es posible un "examen abstractamente explicativo" que no encontramos en las "culturas orales primarias", las cuales poseen sabiduría, pueden aprender, pero no "estudian". La ciencia, la filosofía, la historia, la explicación de la literatura y el arte ocurren en la escritura (Ong, 2016, pp. 43, 44, 52). Eurocentrismo significa, según Samir Amin, que el Occidente europeo es "el mejor de los mundos conocidos hasta ahora [...] los otros mundos [...] solo pueden progresar a condición” de imitarlo (1989, pp. 102-103). Europa es la medida en términos epistemológicos, éticos,

\footnotetext{
${ }^{1}$ Agradezco los valiosos aportes a mi trabajo de la maestra Roxana Zermeño Rivas y del maestro Marco Antonio Romero Ramos.
} 
políticos y estéticos para los otros mundos, que difícilmente la alcanzarán —acarreando una frustración constante-, no por inferioridad, sino porque responden a historias y contextos culturales diferentes. Del argumento de Ong pueden derivarse posiciones eurocéntricas. Hay prejuicios que caracterizan a las culturas indígenas como exclusivamente orales y carentes de escritura, por lo que estarían imposibilitadas para la abstracción y el estudio. Es así porque el parámetro único de comparación es la escritura europea.

Bajo la perspectiva poscolonial, el carácter abstracto del eurocentrismo es criticable. En este no hay un planteamiento de cómo conoce el hombre, en tanto ser humano, sino cómo conoce el hombre blanco, europeo, burgués, heterosexual, y esta manera de conocer se asume como válida para todo tiempo y espacio; se trata, entonces, de un localismo hegemónico que se globaliza. Así, el dominio europeo no fue solo cuestión, como dice Edward Said (2001), de cañones y soldados, sino también de ideas.

Spivak afirma que en la filosofía hay ideología. En el siglo XVIII se fabricó científicamente una autorrepresentación alemana y de la otredad que brindó las coartadas para "la dominación, la explotación y la violación epistémica" (Spivak, 2010, p. 19). En la razón pura kantiana, asegura la filósofa, hay conceptos-metáfora que la asemejan a un relato que terminó por legitimar el dominio europeo. Según Samir Amin (1989), la lingüística dominante en el romanticismo racista del siglo XIX ideó un prototipo de lengua griega que eliminó todo préstamo oriental, dando cabida al mito de la "pureza aria” de Grecia, origen del eurocentrismo. Para Homi Bhabha (2002), la representación viene acompañada de estereotipos y fetiches: sin demostración lógica o comprobación empírica, Europa asume un origen puro que la hace repudiar lo que no sea su cultura.

Sostiene Aimé Césaire (2006) que el humanismo occidental —filósofos, escritores, historiadores, arqueólogos, religiosos, misioneros, psicoanalistas, sociólogos de los siglos XIX y XX- fue cómplice de la representación de europeos como clase dirigente, aptos para pensar y hacer ciencia, amos, autónomos, viriles y con el derecho de explotar la riqueza; y de la representación de indios, amarillos y negros como esclavos, débiles, dependientes, desprovistos de honor, desidiosos, salvajes y, dados sus climas tropicales, incapaces de pensar. Estos, digamos, representan el estado bruto de la humanidad; aquellos, la madurez.

El problema de la representación está ligado al de la subalternidad. Spivak (2003), apoyándose en Marx, caracteriza al subalterno como aquel que "no puede representarse a sí mismo, debe ser representado". Aunque la manera propiamente spivakiana de definirlo es como aquel que no puede autosinecdoquizarse (2017). En una sinécdoque se puede tomar el todo por una de sus partes. Por eso Spivak dice poder autosinecdoquizarse: toma una de sus características y omite otras para representarse a sí misma. El subalterno no puede hacerlo, carece de capacidad performativa, no puede hablar y, si habla, no es escuchado ni leído, es decir, no genera interlocución. Edward Said (2016) muestra cómo Oriente es lo que Europa representa de él. Representarlo es conocerlo y dominarlo. Es un problema semejante al que vio Edmundo O'Gorman (2006): América no fue descubierta sino inventada por Europa; en 1507 apareció en el mapamundi de Waldseemüller la "Tierra de Américo".

La representación es un problema sutil. Spivak busca generar una infraestructura para que el subalterno pueda autosinecdoquizarse, pero advierte que puede provocar lo contrario. Los intelectuales de las excolonias que migran a universidades como las de Estados Unidos - a los que llama poscoloniales diaspóricos - corren el riesgo, al hablar de o por sus identidades y culturas, de esculpirlas y museificarlas para el consumo trasnacional. En Chandra Talpade Mohanty (2008) aparece una idea similar. No solo las feministas occidentales representan de manera homogénea a la mujer del tercer mundo, también 
lo hacen las intelectuales de este, porque estudian bajo los mismos principios y métodos de sus colegas primermundistas. Entonces, la poscolonial diaspórica, como afirma Spivak, podría contribuir al colonialismo interno en los países de origen y al neocolonialismo global.

El problema es diferente en Said (1994). Para él, el intelectual está dotado de la facultad o arte de representar, primordialmente, al subalterno. El intelectual debe estar en el "mismo barco que el débil y no representado", el de los olvidados o ignorados, y tiene la responsabilidad de "desenterrar lo olvidado" y denunciar las violaciones de los poderosos a la libertad y la justicia. El crítico, escribe Said: "es responsable [...] de articular aquellas voces dominadas, desplazadas o silenciadas por la textualidad de los textos. Los textos son un sistema de fuerzas institucionalizado por la cultura dominante" (2004, p. 77)

La condición subalterna aparece con claridad en el problema de la traducción, como el caso del sati que expone Spivak (2003). Sati es el femenino de sat que significa verdad, lo bueno, lo justo. Sati quiere decir, en estricto sentido, buena esposa; sin embargo, los ingleses lo tradujeron como viuda buena que se inmola en la pira del esposo. Esto significó una absoluta incomprensión inglesa que impuso una constricción ideológica a las mujeres desde una voz arrogante, supuestamente transparente y racional, que carece de interés por conocer al otro desde sí mismo e ignora todo aquello que no congenie con su visión. Ejemplos de este problema hay varios. Según Gordon Brotherston (1997), la interpretación de los libros del cuarto mundo estuvo perturbada por la traducción que hizo Lévi-Strauss de las unidades "míticas" para elaborar sus Mythologiques, pues homogeneizó la diversidad de fuentes, desde dictados en lengua indígena hasta informes de misioneros europeos de hace siglos. De ahí que Spivak (2009) apueste por no limitar la traducción a las lenguas, sino traducir textos sociales de una cultura a otra, bajo un marco ético y una mediación intercultural que supone el conocimiento profundo de ambas.

No es mi intención exponer en su conjunto el debate poscolonial, sino apoyarme de sus líneas generales para cuestionarnos de manera crítica el sentido de conceptos como oralitura, con el propósito de no obviar discusiones que puedan precisar sus alcances y límites y contribuir a delimitar su lugar en las agendas de pensamiento latinoamericano.

\section{Interrogantes en torno a la oralitura desde el problema de la subalternidad}

Para Carlos Huamán (2007), la tensión entre oralidad y escritura en la literatura no se restringe a una cuestión estética pues se vincula al dominio y la conquista del otro. En El zorro de arriba y el zorro de abajo, de José María Arguedas, la oralidad quechua es llevada a la racionalidad de la escritura, lo cual conlleva la recuperación de espacios culturales perdidos desde la Conquista. Hubert Malina (2018) explica cómo para Occidente las culturas con historia poseen escritura; mientras, la oralidad es reducida a mitos, aunque para los indígenas sea un conocimiento complejo y el sentido mismo de la existencia humana. La lengua castellana es colonizadora, en tanto se arroga el derecho de decir "tú serás esto", y es una lengua de posesión. Recordemos: "Tierra de Américo". Hubert Malina, para ilustrar esto, apunta que en español decimos "cerro de la luciérnaga", aquel pertenece a esta, y en mèphàà es "cerro luciérnaga", el cerro puede transformarse en luciérnaga.

La escritura y la oralidad, como asegura Cornejo Polar (1994), son dos racionalidades diferenciadas, pero con fuertes interacciones entre sí. Se entrecruzan con el arte y la literatura dando lugar a expresiones estéticas difíciles de definir. Walter Ong sugiere que, en contraste con la escritura, cuya 
expresión artística está en la literatura, aún no contamos con la expresión artística adecuada de la oralidad. Literatura oral es, para Ong, un término absurdo, pues literatura "refiere a las letras en cuanto a su origen (literae) del alfabeto", de ahí que prefiera hablar de "formas artísticas verbales", escritas u orales (2016, pp. 50-51).

En este marco, quisiera situar la "intensificación literaria” llevada a cabo por indígenas latinoamericanos que, a decir de Roberto Viereck (2012), ocurrió a partir de los años setenta del siglo pasado, la cual reivindicó la oralidad y se asoció con la resistencia cultural, la reafirmación de la identidad, la revitalización de lenguas y la preservación de la memoria y la cosmovisión indígenas. Algunas propuestas para dar nombre a esa forma artística verbal, oral, las encontramos en la oralitura, el etnotexto y la etnoliteratura. Dado el propósito de este artículo y por motivos de espacio, expongo de forma sintética algunos de sus rasgos, particularmente sobre oralitura. Veremos cómo suponen afirmaciones que nos conectan con el problema de la subalternidad. Busco, de manera introductoria, problematizarlos conceptualmente para precisar en trabajos posteriores el lugar de estos en los intentos por nombrar aquella forma artística verbal, oral.

Para Simón Marchán Fiz (2008), el urinario de Duchamp es el epítome de la estética actual, la cual se originó por diversas discusiones, una de ellas fue la que despertaron Manet, Courbet y Rodin. En ocasiones el jurado invalidaba sus obras como arte, mientras la crítica y el público las afirmaban como tales; a veces, era al contrario. Un debate que contribuyó a la definición moderna de arte fue el suscitado por el Pájaro en el espacio de Brancusi. Los argumentos en contra lo vieron como un producto hecho en serie y una mala representación de la naturaleza, pues no parecía pájaro. La réplica duchampiana asumió que la obra no imitaba la realidad, sino que, por sus formas abstractas, la interpretaba. Finalmente, el Pájaro fue considerado arte. ¿Cómo definir lo que es arte? ¿Cómo se complejiza su definición en obras como la Fuente? ¿Por qué esta es arte? Por una doble complicidad, dice Marchán Fiz, un "autoproclamado artista" declara que "algo es arte", "definición nominalista", y ese algo es aceptado en una exposición, lo que legitima el "objeto en su condición artística" y a "su autor como artista", "definición institucional” (2008, p. 22-23).

En un primer momento, estas obras se entendieron desde una concepción canónica y, de manera paulatina, se construyeron modos más justos de apreciarlas. Algo análogo sucede con la oralitura y los oralitores que, estemos o no de acuerdo, ya son estimados por lo que Marchán Fiz llama "institución arte"; pensemos, por ejemplo, en los premios y becas otorgados sobre oralitura. ${ }^{2}$ La discusión está abierta.

Es complicado delimitar los términos, a veces se confunden entre sí. Según Hugo Niño $(1998,2007)$ y Nina S. de Friedemann (1999), oralitura es un neologismo africano que pretende ubicarse al nivel de la literatura, como se observa en la obra de Yoro Fall. Ha sido definida como la forma artística verbal oral de indígenas colombianos (Toro, 2014), como expresión estética de la oralidad de una tradición étnica (De Friedemann, 1999) y como el proceso de traducir lo oral a lo escrito (Malaver, 2003). Se dice que la oralitura y el etnotexto trastocan las fronteras disciplinares por la recreación ficcional de la tradición oral amerindia o afroamericana elaborada por un investigador-escritor — no necesariamente indígena- que transita entre la etnografía y la literatura (Malaver, 2003; Sánchez, 2007). Es la misma definición que De

\footnotetext{
${ }^{2}$ Como el Premio Nacional de Literatura de Chile 2020 concedido a quien se autodefine como oralitor: Elicura Chihuailaf, y recordemos las Becas de Creación en Oralitura Indígena del Ministerio de Cultura de Colombia.
} 
Friedemann apunta para la etnoliteratura. Esta es definida por Diana Toro como la "reelaboración escrita de las formas orales" (2014, p. 241), idea muy similar a la de Malaver para la oralitura.

El etnotexto, de acuerdo con Niño $(1998,2007)$, se vincula con la oralidad, la mitología y las tradiciones; no se restringe a la noción occidental de literatura, a la oposición realidad/ficción, ni a una estética puramente verbal. Es un relato, un performance, una ritualización sostenida por la autoridad de la comunidad que da lugar, desde los márgenes, a una visión indígena e intercultural.

Según Niño, no hay consenso en estos términos pero sí coincidencias. No son reducibles a los cánones, resisten a las teorías hegemonizantes y se oponen al colonialismo cultural (Niño, 2007; Malaver, 2003). La oralitura y el etnotexto no se limitan a una esfera morfológica, tienen un alcance "cosmovisivo", pues suponen un sistema epistemológico, lógico y cultural excluido por Occidente. El texto letrado y lineal, en contraposición con el etnotexto o la oralitura, difícilmente puede hablar "sobre los manejos del cuerpo, del espacio físico, de los ciclos rituales, de un tiempo que es circular, del silencio y de la secretividad misma" (Niño, 1998, p. 224).

Hugo Jamioy (Kamsa), Anastasia Candre (Huitoto) y Estercilia Simanca Pushaina (Wayuu) son oralitores en los que piensa Luis Alfonso Barragán (2016) cuando afirma que la reapropiación que hacen de la tradición oral y escrita posibilita, en Colombia, la renovación de los corpus y cánones literarios y, también, culturales, éticos y políticos. Barragán ve en la oralitura un sistema de conocimiento asentado en una "sabiduría ancestral indígena" que, entre otros modos comunicativos, mantiene "una forma de dialogismo con lo otro", de ahí su cercanía con una axiología comunitaria. La oralitura no se reduce a la palabra en el papel, se trata de un complejo performativo que entrecruza las dimensiones estética, política, cultural, social, ética y pedagógica. Lo marginado por la crítica literaria canónica tiene, para Barragán, en la oralitura un lugar "desde dónde actuar y, sobre todo, desde dónde hablar" (2016, pp. 359-360).

Nociones como oralitura pueden ser vagas o ambiguas, pero, para Juan Guillermo Sánchez Martínez (2007), es preferible "ensanchar los términos que establecerlos", abrirse a la diversidad y dejar de insistir en concepciones homogeneizadoras que no reconocen la variedad de expresiones artísticas. Estoy de acuerdo con diversificar las herramientas conceptuales con las que contamos porque, en ocasiones, ya no nos permiten comprender problemas actuales, pero tampoco podemos dejar de plantearnos preguntas sobre ellas para problematizar y complejizar su estudio de forma crítica.

¿Cómo entendemos a partir de la oralitura la tensión entre oralidad y escritura? ¿Cuáles son las metodologías para analizar la oralitura, el etnotexto o la etnoliteratura? ¿La oralitura recupera espacios culturales perdidos desde la Conquista? ¿Es una expresión de emancipación del subalterno? ¿Hay en ella una autosinecdoquización indígena? ¿Hay en la oralitura una liberación de las constricciones ideológicas impuestas por las traducciones e interpretaciones europeas sobre los indios? La autotraducción que hacen varios oralitores, de su lengua al castellano, ¿implica una mediación intercultural abierta a la traducción de un texto social de una cultura a otra? ¿Son los oralitores, intelectuales al estilo de la concepción de Said? ¿Están del lado de los débiles y de los no representados? ¿La oralitura articula las voces dominadas y silenciadas por la textualidad del texto de la cultura dominante? ¿La oralitura representa un proyecto de descolonización del conocimiento? O, por el contrario, ¿puede devenir en una museificación de la identidad indígena y en su mercantilización para el consumo trasnacional? Al representarse a sí mismos y a sus culturas, ¿¿los oralitores corren el riesgo de contribuir a la colonización interna en sus países de origen y al neocolonialismo global? 


\section{La oralidad y la escritura como problema complejo}

Las lenguas y la oralidad indígenas están interconectadas, ¿por qué entenderlas en contraste con la escritura? Jacques Derrida asegura que "los 'conceptos' filosóficos [no pueden] trascender las diferencias idiomáticas” (Spivak, 2009, p. 25). Por ejemplo, en la lengua de los akan, explica el filósofo ghanés Kwasi Wiredu, no puede traducirse el criterio cartesiano cogito ergo sum porque no hay palabras que expresen tal idea (De Sousa Santos, 2013). La lengua de los tojolabales y tseltales, en México, se caracteriza por una desinencia, el -tik, que significa "nosotros" (Lenkersdorf, 2002). El "yo" se desdibuja en estas lenguas. ¿Qué sentido tiene en ellas el problema del Yo cartesiano? ¿Qué consecuencias tienen las diferencias lingüísticas en campos como la filosofía, la ideología o la cultura?

En 2017 se presentó en la Real Academia Española el proyecto "La lengua navega a América" para celebrar el encuentro entre dos mundos. La alegoría es sugerente. Los navegantes eran colonizadores. La escritura en América se fetichizó (Lienhard, 2003), casi por un acto de magia los indios debían convertirse al cristianismo al mostrarles la Biblia. Como sucede en la crónica de Cajamarca donde Vicente Valverde, en 1532, hace lo propio con Atahualpa, quien no sabe cómo manipularla y la arroja al piso. Para Cornejo Polar (1994), se muestra aquí la inconmensurabilidad entre la cultura letrada-libresca y la oral, el "grado cero" de su vínculo donde se explicitan sus diferencias y su recíproca ajenidad y repulsión.

No obstante, en la época precolombina, como sostiene Brotherston (1997), había una conciencia del problema de la escritura, pensemos en los códices mesoamericanos o los cordeles o quipus de los Andes. Brotherston explica cómo Lévi-Strauss neutralizó evidencia que contrastaba con su tesis de una América exclusivamente oral. Para Jaime García Leyva (2012), la oralidad fue una resistencia cultural de los indios ante la destrucción de su escritura.

El debate poscolonial nos recuerda que las formas de ser, hablar, leer, escribir, pensar o percibir, no son homogéneas sino más bien diversas, de acuerdo con la cultura y la lengua. Una donde se gestó el cogito cartesiano tendrá repercusiones epistémicas, éticas, políticas y estéticas diferentes a otra donde aquel sea imposible de traducir o se caracterice por un nosotros. Si el cerro es una luciérnaga hay más probabilidades de tener un cuidado ético con él, que si lo consideramos una de las propiedades del hombre.

Rivera Cusicanqui (2018) distingue dos modos de pensar en aymara: lup'iña y amuytaña. El primero refiere a lo racional, a pensar con la cabeza clara; el segundo, a pensar con el corazón, los pulmones y el hígado. La respiración y los latidos son pensamiento, de ahí que exista un pensar de la caminata, del ritual, de la canción y del baile. Difícilmente coincidiría con esta concepción el pensamiento moderno europeo, arraigado en nuestra educación formal y que incubó maneras de pensar y sentir como naturales marginando otras. Las lenguas y la oralidad indígenas están íntimamente entrelazadas y reivindican lo puesto en la periferia. ¿Cómo cambiaría la visión del mundo si pensamos, no bajo el criterio cartesiano, sino con el corazón y asumimos que la naturaleza es un ser vivo?

Es complejo el problema de definir el papel de la oralidad en la literatura porque interactúa con la cultura, la identidad, la memoria, la tradición, y emergen producciones artísticas que, igualmente, aún no encuentran poéticas y metodologías definidas para analizarlas.

¿Cómo se ha estudiado, entonces, la relación entre oralidad y escritura? Imposible detallar una respuesta aquí, pero pueden bosquejarse antecedentes claves. Para Cornejo Polar, hay una distinción entre la voz y la letra en los gestos y las palabras entre Atahualpa y Valverde, que no son parte de la literatura, 
pero originan "una compleja institucionalidad literaria" (1994, p. 23). En la Nueva crónica y buen gobierno de Guamán Poma, Roberto Viereck (2012) sugiere que es la escritura (visión europea) la que se ajusta al texto oral (visión andina), de ahí que se cuestione si son los dibujos los que ilustran la crónica o viceversa. Un salto enorme en el tiempo, pero la referencia en estos estudios a José María Arguedas es recurrente. Se ha dicho que su obra revela cómo la sintaxis quechua se inserta en el castellano y cómo los personajes andinos parecieran expresarse sin la mediación del narrador occidental. Esta quechuización del castellano produce, dice Carlos Huamán, una "mistura" lingüística que se fusiona de manera compleja con universos culturales diferentes (2007, p. 178).

En este marco, Cornejo Polar afirma que es necesario revalorar las literaturas étnicas y precisar las categorías de análisis que expliquen ese "enredado corpus". Algunas propuestas las encontramos en la literatura transcultural de Ángel Rama, la literatura escrita alternativa de Martin Lienhard, la literatura otra de Edmundo Bendezú, el discurso andino transcultural de Carlos García Bedoya y la literatura heterogénea, como prefiere llamarla Cornejo Polar.

Un antecedente valioso es la narrativa indigenista. Julio Rodríguez-Luis (1980) sostiene que los escritores de la región andina son los más universalmente identificados con esta y que la publicación de sus novelas no fue esporádica, sino una manifestación continua. Reconoce la producción de nuestro país, pero asegura que el "indigenismo en la literatura mexicana de las últimas décadas, tiende a ser fragmento más que contenido principal” (1980, p. 11).

Hay en la narrativa indigenista una disputa entre literatura y antropología. Me refiero al problema de la recreación ficcional que termina por hacer el antropólogo de su testimonio etnográfico. En este se expresa la voz del informante, aunque mediada por la del investigador, y no es fácil distinguir si estamos ante un estudio antropológico o un relato. Para el caso mexicano hay estudios muy ilustrativos. Ana Lourdes Álvarez Romero (2019) examina en Juan Pérez Jolote: biografía de un tzotzil (1948), de Ricardo Pozas, cómo se problematizan las fronteras entre antropología y literatura: la obra parece una monografía tsotsil pero también una novela picaresca. Álvarez sugiere no entender la relación entre disciplinas bajo una lógica disyuntiva, como lo exige el canon, sino de una manera dialógica y compleja.

Como vimos, el problema que plantea el etnógrafo-escritor está en la oralitura y el etnotexto, pero no se limita a ello, sino que complejiza la tensión entre oralidad y escritura. Las palabras de Humberto Ak'abal para definir su quehacer nos ayudan a aclarar el de los oralitores; en entrevista con Roberto Viereck (2012), dijo: "yo no solo soy transcriptor de oralidades, porque no soy antropólogo [...] Integro en mis textos aspectos de la oralidad, pero detrás de todo eso está también mi experiencia de vida y el trabajo de escribir y reescribir". En las pláticas cotidianas con la gente de su pueblo encuentra los temas de su poesía, característicos de la identidad k’iche': el amor a la naturaleza, la humanización de los animales, los objetos y los espantos. Por eso afirma que la oralidad es el "cordón umbilical" con sus raíces. Pablo González-Casanova Henríquez (1998) asocia la oralitura con el diálogo franco y la conversación, minados por la imprenta y el alfabeto traído de Europa. Si para la comprensión de la literatura latinoamericana es necesario el estudio de aquella tensión, la oralitura provee un marco para este.

Es sugestiva la respuesta de Ak’abal a la pregunta de Viereck sobre si su poesía es, al confluir con el castellano, menos k'iche’ y más bien bilingüe o multicultural. Para el poeta no es así, pues ambas lenguas son independientes: "la estética de escritura de cada una mantiene su propia expresión, no interfieren 
en su sentir". Más allá de si estamos o no de acuerdo con Ak’abal o Viereck, el problema vigente es el de la confluencia entre las lenguas y entre la oralidad y la escritura, si son o no independientes, si se superponen entre sí o no y cómo analizar tal confluencia.

Miguel Rocha Vivas (2018) reúne un corpus de oralitura en Colombia. Aparece en él un poema de Hugo Jamioy, del que recupero un fragmento: "los taitas van llegando, / vienen susurrando su canto. / Vístete con tu lengua”; estos versos están acompañados con la imagen de un chumbe. El chumbe es considerado un libro. Para Pastora Juajibioy, madre de Hugo Jamioy, tejer un chumbe es una manera de escribir, es, entonces, una lengua que viste al cuerpo. Esto se entrelaza con una "comunicación gráfica corporal"; el que los taitas, las autoridades, vengan con su canto refiere a la oralidad indígena, y el verso escrito remite al campo literario (Rocha, 2018, p. 50). ¿Qué produce en conjunto esta interacción? ¿Cómo podemos apreciarla estéticamente?

Rocha Vivas propone un par de nociones: visiones de cabeza y textualidades oralitegráficas; prefiere hablar de nociones "para nombrar algo que existe pero que no está clara o plenamente identificado" (2018, p. 11). Textualidades oralitegráficas suponen la interacción entre lo oral, lo literario y lo gráfico-visual, producciones bilingües o en un castellano con préstamos de lenguas indígenas. Visiones de cabeza alude a la autorrepresentación indígena que subvierte las miradas hegemónicas sobre las culturas nativas. Así, el poema citado puede leerse como textualidad oralitegráfica y, el vestirse con la lengua, sugiere una visión de cabeza: la posibilidad de autosinecdoquización indígena.

No estamos ante objetos de estudio conocidos, enmarcados en teorías ampliamente documentadas y bajo la guía de herramientas probadas. Se trata de problemas para los cuales aún no contamos con las palabras para nombrarlos y estudiarlos con precisión, están en construcción. ¿Por qué "inventar" términos como oralitura, preguntarán algunos, si contamos con los suficientes para explicar sencillamente el problema? ¿Por qué no se usó la vieja navaja de Ockham? Quizá ya se usó en exceso.

\section{Para la construcción interdisciplinaria de metodologías}

La oralitura, el etnotexto y la etnoliteratura integran el conflicto entre oralidad y escritura. En una de sus acepciones la oralitura no contempla la escritura, por eso se entiende como expresión estética de la oralidad y, el etnotexto, como elaboración escrita de la oralitura. Pero esta también se concibió como la traducción de lo oral a lo escrito. Además, en estos términos permea la recreación literaria de la tradición oral étnica. Pero se complejizan porque se toman como sistemas culturales y de conocimiento en interlocución con la otredad, que reivindican la palabra de los excluidos y una visión indígena como contraparte de la pragmática establecida.

La palabra en la oralitura se inserta en un complejo simbólico. Su belleza, la identidad a la que está ligada, el sentido que otorga a la existencia, llama el interés literario, antropológico y filosófico, por decir algunos. Pero no satisface a ninguno. Intuimos que estamos ante algo holístico imposible de descomponer en sus partes para analizarlas por separado; debemos verlas en sus relaciones, como sucede con un sistema. Pero nos acercamos con lo que tenemos a la mano, principios y herramientas canónicas, y exigimos satisfacer criterios que le resultan ajenos. La oralitura ni es literatura, ni documento etnográfico, ni filosofía.

Para Cornejo Polar la literatura latinoamericana conlleva un "sistema complejo" (1994, p. 20). Un sistema complejo requiere de un estudio interdisciplinario (García, 2013), por lo tanto, es válido acercar- 
nos a la literatura a través de la interdisciplina. Esta la entiende Olga Pombo (2013) como "fecundidad recíproca" entre disciplinas: se importan conceptos o metodologías de una disciplina para analizar problemas en otra.

En el debate poscolonial hallamos pistas para elaborar marcos de análisis interdisciplinarios. Spivak es una muestra de esta fecundidad recíproca. Vimos cómo utilizó la sinécdoque para definir la condición subalterna, pero plantea otros casos similares. Por ejemplo, deconstruyó tropológicamente (crítica literaria) y leyó desde la perspectiva del informante nativo (etnografía) la filosofía pura de Kant. Hay una afirmación en el juicio teleológico kantiano: la naturaleza le debe estar sometida al hombre. En Spivak, el informante nativo - cosificado por la investigación al entenderlo como depósito pasivo de donde extraer información - se convierte en lector avispado que revisa entre líneas a Kant y advierte en aquella afirmación metáforas y la representación de Europa como legisladora global. Si la razón pura —esto lo indica la deconstrucción tropológica - se apoya de metáforas no se distingue de una narrativa. Lo que está sugiriendo Spivak es que el dominio europeo se sustenta en un cuento escrito por Kant.

El cruce interdisciplinario nos permite nombrar problemas contemporáneos que difícilmente se analizan con categorías preconcebidas. Este cruce es sugestivo para estudiar las formas artísticas orales indígenas, las cuales resultan demasiado etnográficas para la literatura y, para la antropología, demasiado literarias, por lo que ambas prefieren dejarlas en el terreno de la otra (Malaver, 2003). La poética occidental no auxilia en este problema, incluso deforma nuestra mirada, como señala Jerome Rothenberg (2006), quien propone una etnopoesía e investigar en un marco transcultural las poéticas posibles. Enrique Flores (2015) opta por un abordaje complejo e interdisciplinario, en particular, vincular la poética con la etnología para analizar los libros del cuarto mundo. Álvarez (2019) intuye la necesidad de un marco conceptual que valide la interacción entre disciplinas. Lo encuentra en la semiosfera de Lotman, con la cual justifica los contactos entre discursos diversos y sus formas de traducción mutua.

Hay un problema de tipo epistemológico al validar el uso de herramientas o conceptos de una disciplina para entender problemas de otra. Requerimos también vigilar en términos epistemológicos los marcos conceptuales y metodológicos de los que nos apoyamos para analizar nuestros objetos de estudio.

En el XV Congreso Internacional de Literatura: Memoria e Imaginación de América Latina y el Caribe, celebrado en la Universidad de Guanajuato en 2019, Ángel Héctor Gómez Landeo presentó una recuperación de relatos indígenas del shipibo-conibo de la amazonia peruana. Parte de su marco analítico descansaba en Vladimir Propp. Pues bien, el teórico del cuento ruso tiene una marcada influencia de la estética formalista de Kant, que la encontramos en su Crítica del juicio.

En esta aparecen algunos prejuicios del filósofo contra mujeres, orientales e indios. Para Kant (2007), una mujer que piensa haría bien en llevar barba. Hay un pasaje donde afirma que los "voluptuosos del Oriente" experimentan un goce cuando comprimen su cuerpo y pliegan sus músculos y articulaciones, lo dice para ilustrar el caso contrario al sentimiento de lo sublime. Este no ocurre en un goce restringido a lo sensible, pues debe relacionarse con el pensamiento, lo intelectual y la razón. Los orientales quedan circunscritos a la sensibilidad y no participan de la razón, por lo tanto, no experimentan el sentimiento de lo sublime. Finalmente, los aborígenes de Nueva Holanda y Tierra del Fuego no son sujetos del juicio en la Crítica, no pueden apreciar estéticamente y están fuera de la idea de hombre del filósofo de Königsberg (Spivak, 2010).

Apoyarnos de Propp implica asumir a Kant. ¿Cómo estudiar relatos indígenas a partir de marcos teóricos y metodologías provenientes, en sus raíces, de filosofías que suponen una falta de pensamiento 
y capacidad estética en mujeres, orientales e indios? No se trata de evitar el uso de herramientas con las que ya contamos, sino de vigilar su coherencia al momento de aplicarlas. Tenemos naturalizados modos de aprender, apreciar y sentir que, sin embargo, fueron fabricados en un momento y espacio específicos, son modos hegemónicos que descartan de manera prejuiciada lo que no se acomoda a sus criterios. Colonizan en el sentido que le da Mohanty (2008) a esta palabra: suprimen con violencia la heterogeneidad. ¿Cómo construir modos de análisis justos en términos epistemológicos y metodológicos?

Cuando los españoles llegaron al Tawantinsuyu vieron que Atahualpa y Huáscar sostenían una lucha fratricida por el trono, el cual debía pertenecer al primogénito. Esta fue una interpretación prejuiciada. Los indios restablecían el equilibrio simbólico que perdió su padre, el Inca Huayna Cápac, por abandonar el Cuzco y vivir en Tumipampa. Había una crisis primordialmente religiosa y sagrada que los hermanos solucionaban en un ritual. La primogenitura no existía en la cultura andina, sino que había un rango de edades de acuerdo con las tareas que realizaban las personas (Pease, 1991). Las palabras de los desembarcados malentendieron la situación.

Algo análogo sucede con el problema que planteo. Nombramos nuestros objetos de estudio con los lenguajes que tenemos, pero estos responden a un contexto particular y a las epistemologías que les dieron origen. Nos determinan a ver cosas y nos imposibilitan ver otras. Las formas artísticas verbales orales llaman la atención de disciplinas diversas, pero no satisfacen sus estándares como para adoptarlas legítimamente. ¿Cómo estudiarlas? Una respuesta está en la interdisciplina y, en esta, no podemos perder de vista las interrogantes de Roberto Follari: "qué disciplinas vienen a cuento, qué aporta cada una, y en qué dirección epistémica" (2013, p. 120).

\section{Consideraciones finales}

La oralitura tiene el cobijo de las definiciones nominalista e institucional. Hay quienes se autoproclaman oralitores y declaran que algo es oralitura y hay premios y becas que los legitiman. Oralitura es un esfuerzo por nombrar la expresión artística de la oralidad relacionada con la escritura. El examen de esta relación es vital para la literatura, pero también para la historia, la ideología y la cultura en general, como se aprecia en la colonización epistémica de América. Los rasgos de la oralitura, el etnotexto o la etnoliteratura nos recuerdan el debate poscolonial y uno de sus problemas centrales: la subalternidad, definida como la imposibilidad de autosinecdoquizarse. No falta razón al asociar al europeo con la subalternización del negro, el amarillo o el indio. Europa es indefendible (Césaire, 2006). Sin embargo, la subalternización es casi invisible, ocurre al hablar por los otros o al usar los métodos represores de la heterogeneidad.

¿Hay una autorrepresentación indígena en la oralitura? ¿Constituye la emancipación indígena de su condición subalterna? ¿Por qué la oralitura habría de trascender aquellas formas colonizadoras más sutiles? ¿Por qué no habría de perpetuar aquella condición? El debate no está cerrado porque los neologismos y las herramientas de análisis están en construcción. La recreación ficcional del testimonio etnográfico es un antecedente clave, pero no agota la discusión. Pensemos en el poema de Jamioy elaborado con textos orales, literarios y gráficos. Si el chumbe es un libro, ¿cómo lo leemos? Y ¿cómo analizamos un chumbe que, gráficamente, está debajo de versos que, usando la metáfora de Cornejo Polar, se escribieron en el aire? ¿Cuáles metodologías seguimos para analizarlos como un todo? 
Mi propósito fue esbozar condiciones y criterios mínimos para una búsqueda crítica de alternativas al problema. Si no sabemos con precisión cómo nombrar la expresión artística oral, tampoco cómo estudiarla. Necesitamos abrirnos a la interacción entre disciplinas, pero también a marcos epistemológicos que validen esa interacción. Una vía es tomar marcos prefabricados, pero al menos habremos de examinar su congruencia con el objeto de estudio. Esta vía es riesgosa para un objeto aún no identificado del todo, pues quizá veremos primogenituras o luchas fratricidas donde no las hay. La otra vía es construirlos. En esta, el objeto, su epistemología y su metodología se definirán en un ir y venir entre ellos. Nos acercamos al objeto, regresamos a los modos de teorizarlo y de analizarlo, los ajustamos y volvemos a él hasta dar con la palabra para nombrarlo y con el modo de analizarlo.

Toma aquí mucho sentido la propuesta de Mabel Moraña (2018) de un programa político-filosófico decolonizador para América Latina que no sea servil del pensamiento europeo, pero que tampoco lo omita: "ni dependiente, ni fundamentalista". Se trata de una apropiación crítica de Occidente y de la recuperación de un pensamiento en lenguas indígenas.

Podemos inspirarnos en lo ch'ixi de Rivera Cusicanqui (2010), un concepto aymara que discute con principios filosóficos canónicos como el de no contradicción. Lo ch’ixi no es fusión de contrarios, sino coexistencia conflictiva entre ellos, sin anularse. El gris es un color ch'ixi, pues de lejos lo vemos, pero al acercarnos encontramos una superposición de puntos negros y blancos. El gris es y no es blanco, es y no es negro. La asunción de una epistemología ch’ixi traería consecuencias estéticas diversas. Parte del problema que vimos es que las expresiones artísticas orales indígenas están constreñidas a una lógica de ser o no ser. A manera de hipótesis, tales expresiones pueden adquirir un significado más justo al comprenderlas desde una yuxtaposición de puntos provenientes de dominios disciplinares múltiples y de saberes excluidos por la academia —donde los opuestos coexistan—, que encorsetarlas en cánones disciplinares que se repelen mutuamente.

\section{Referencias}

Álvarez Romero, A. L. (2019). La frontera entre la antropología y la literatura en Juan Pérez Jolote. LiminaR. Estudios Sociales y Humanísticos, XVII(1), 145-157. 10.29043/LIMINAR.Vl7Il.651

Amin, S. (1989). El eurocentrismo. Crítica de una ideología. Siglo XXI.

Barragán, L. A. (2016). Palabra de los bordes que transita a través: la oralitura como posible apertura políticocultural. Catedral Tomada. Revista de Crítica Literaria Latinoamericana, 4(7), 339-361. 10.5195/ct/2016.146

Bhabha, H. K. (2002). El lugar de la cultura. Manantial.

Brotherston, G. (1997). La América indígena en su literatura: los libros del cuarto mundo. Fondo de Cultura Económica. Césaire, A. (2006). Discurso sobre el colonialismo. Akal.

Cornejo Polar, A. (1994). Escribir en el aire: ensayo sobre la heterogeneidad socio-cultural de las literaturas andinas. Horizonte.

De Friedemann, N. S. (1999). De la tradición oral a la etnoliteratura. Oralidad. Anuario para el Rescate de la Tradición Oral de América Latina y el Caribe, 10, 19-27. http://www.lacult.unesco.org/docc/oralidad_10_1999.pdf

De Sousa Santos, B. (2013). Descolonizar el saber, reinventar el poder. Trilce.

Flores, E. (2015). Etnobarroco. Rituales de alucinación. Universidad Nacional Autónoma de México.

Follari, R. (2013). Acerca de la interdisciplina: posibilidades y límites". INTERdisciplina, 1(1), 111-130. http:// revistas.unam.mx/index.php/inter/article/view/46517

García Leyva, J. (2012). Oralidad, historia y educación de Na Savi. En F. González, H. Santos, J. García et al. (coords.), De la oralidad a la palabra escrita. Estudios sobre el rescate de las voces originarias en el sur de México (pp. 115-138). El Colegio de Guerrero.

García, R. (2013). Investigación interdisciplinaria de sistemas complejos: lecciones del cambio climático. INTERdisciplina, 1(1), 193-206. http://revistas.unam.mx/index.php/inter/article/view/46517 
González-Casanova Henríquez, P. (coord.) (1998). Cuentos y relatos indígenas, vol. 7. Universidad Nacional Autónoma de México; Centro de Investigaciones Humanísticas de Mesoamérica; Gobierno del Estado de Chiapas; Universidad Autónoma de Chiapas.

Huamán, C. (coord.) (2007). Voces antiguas, voces nuevas. América Latina en su transfiguración oral y escrita, vol. II. Universidad Nacional Autónoma de México; Universidad Autónoma Metropolitana.

Kant, I. (2007). Prolegómenos a toda metafísica del porvenir. Observaciones sobre el sentimiento de lo bello y lo sublime. Crítica del juicio. Porrúa.

Lenkersdorf, C. (2002). Filosofar en clave tojolabal. Porrúa.

Lienhard, M. (2003). La vozy su huella. Juan Pablos Editor.

Malaver Rodríguez, R. (2003). De la oralitura al etnotexto: un ejemplo de aplicación. Enunciación, 8, 27-43. https://revistas.udistrital.edu.co/ojs/index.php/enunc/article/view/2476/3455

Malina, H. (2018). La poesía indígena no es casual, sino necesaria, dice Hubert Malina. Entrevista. Crónica. http://www.cronica.com.mx/notas/2018/1084849.html

Marchán Fiz, S. (2008). Las "querellas" modernas y la extensión del arte. Fabrikart, 8, 14-34.

Mohanty, C. T. (2008). Bajo los ojos de Occidente. Saber académico y discursos coloniales. En Sandro Mezzadra et al., Estudios postcoloniales. Ensayos fundamentales. Traficantes de Sueños.

Moraña, M. (2018). "Hacia una agenda filosófica latinoamericana: bases para un debate”. En M. Moraña (ed.), Sujeto, decolonización, transmodernidad. Debates filosóficos latinoamericanos. Iberoamericana.

Niño, H. (1998). El etnotexto: voz y actuación la oralidad. Revista de Crítica Literaria Latinoamericana, 24(47), 109121. https://www.jstor.org/stable/4530969

Niño, H. (2007). El etnotexto como concepto. Oralidad. Anuario para el Rescate de la Tradición Oral de América Latina yel Caribe, 9, 22-29. http://www.lacult.unesco.org/docc/oralidad_09_22-29-el-etnotexto-como-concepto.pdf

O'Gorman, E. (2006). La invención de América. Fondo de Cultura Ēconómica.

Ong, W. J. (2016). Oralidad y escritura: tecnologías de la palabra. Fondo de Cultura Económica.

Pease G.Y., F. (1991). Los últimos incas del Cuzco. Alianza.

Pombo, O. (2013). Epistemología de la interdisciplinariedad. La construcción de un nuevo modelo de comprensión. INTERdisciplina, 1(1), 21-50. http://revistas.unam.mx/index.php/inter/article/view/46512

Rivera Cusicanqui, S. (2010). Ch'ixinakax utxiwa. Una reflexión sobre prácticas y discursos descolonizadores. Tinta Limón.

Rivera Cusicanqui, S. (2018). Un mundo ch'ixi es posible. Ensayos desde un presente en crisis. Tinta Limón.

Rocha Vivas, M. (2018). Mingas de la palabra. Textualidades oralitegráficas y visiones de cabeza en las oralituras y literaturas indigenas contemporáneas. Universidad de los Andes; Pontificia Universidad Javeriana.

Rodríguez-Luis, J. (1980). Hermenéutica y praxis del indigenismo. La novela indigenista de Clorinda Matto a José María Arguedas. Fondo de Cultura Económica.

Rothenberg, J. (2006). Etnopoética y política/ La política de la etnopoesía. En C. Bernstein, La política de la forma poética [The Politics of Poetic Form]. Torre de Letras. http://writing.upenn.edu/library/Bernstein-Charles_ed Politica-forma-poetica.pdf

Said, E. (1994). Representaciones del intelectual. Paidós.

Said, E. (2001). Cultura e imperialismo. Anagrama.

Said, E. (2004). El mundo, el texto y el crítico. Debate.

Said, E. (2016). Orientalismo. Penguin Random House.

Sánchez Martínez, J. G. (2007). Poesía indígena contemporánea: la palabra (tziij) de Humberto Ak'abal. Cuadernos de Literatura, 11(22), 78-83. https://revistas.javeriana.edu.co/index.php/cualit/article/view/6635

Spivak, G. C. (2003). ¿Puede hablar el subalterno? Revista Colombiana de Antropología, 39, 297-364. https://doi. org $/ 10.22380 / 2539472 X .1244$

Spivak, G. C. (2009). La muerte de una disciplina. Universidad Veracruzana.

Spivak, G. C. (2010). Crítica de la razón poscolonial. Hacia una historia del presente evanescente. Akal.

Spivak, G. C. (2017). Una educación estética en la era de la globalización. Universidad Nacional Autónoma de México; Universidad Autónoma Metropolitana; Fundación Universidad de las Américas; Siglo XXI.

Toro Henao, D. C. (2014). Oralitura y tradición oral. Una propuesta de análisis de las formas artísticas orales. Lingüística y Literatura, 65, 239-256.

Viereck Salinas, R. (2012). La voz letrada. Escritura, oralidad y traducción: diálogos con seis poetas amerindios contemporáneos. Abya-Yala. 